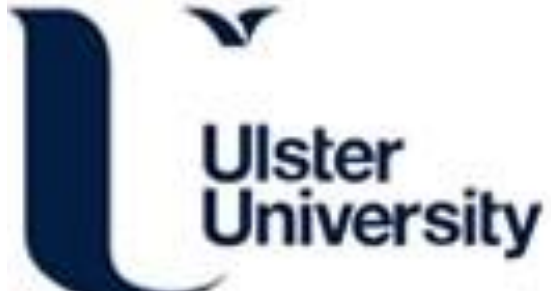

\section{Directed microbial biosynthesis of deuterated biosurfactants and potential future application to other bioactive molecules}

Smyth, T., Perfumo, A., Marchant, R., \& Banat, I. (2010). Directed microbial biosynthesis of deuterated biosurfactants and potential future application to other bioactive molecules. Applied Microbiology and Biotechnology, 87(4), 1347-1354. https://doi.org/10.1007/s00253-010-2592-5

Link to publication record in Ulster University Research Portal

\section{Published in:}

Applied Microbiology and Biotechnology

Publication Status:

Published (in print/issue): 01/08/2010

DOI:

10.1007/s00253-010-2592-5

\section{Document Version}

Publisher's PDF, also known as Version of record

\section{General rights}

Copyright for the publications made accessible via Ulster University's Research Portal is retained by the author(s) and / or other copyright owners and it is a condition of accessing these publications that users recognise and abide by the legal requirements associated with these rights.

\section{Take down policy}

The Research Portal is Ulster University's institutional repository that provides access to Ulster's research outputs. Every effort has been made to ensure that content in the Research Portal does not infringe any person's rights, or applicable UK laws. If you discover content in the Research Portal that you believe breaches copyright or violates any law, please contact pure-support@ulster.ac.uk. 


\title{
Directed microbial biosynthesis of deuterated biosurfactants and potential future application to other bioactive molecules
}

\author{
Thomas J. Smyth • Amedea Perfumo • Roger Marchant • Ibrahim M. Banat • \\ Minglei Chen $\cdot$ Robert K. Thomas $\cdot$ Jeffrey Penfold $•$ Paul S. Stevenson $•$ Neil J. Parry
}

Received: 24 February 2010 /Revised: 26 March 2010 /Accepted: 27 March 2010 / Published online: 20 April 2010

(C) Springer-Verlag 2010

\begin{abstract}
Deuterated rhamnolipids were produced using strain AD7 of Pseudomonas aeruginosa, which was progressively adapted to increasing levels of deuterium in $\mathrm{D}_{2} \mathrm{O}$ and carbon substrates. Fourteen different deuterated rhamnolipid structures, including structural isomers, were produced which is similar to normal protonated structures. There were two main products monorhamnolipid Rha- $\mathrm{C}_{10}-\mathrm{C}_{10}$ and dirhamnolipid $\mathrm{Rha}_{2}-\mathrm{C}_{10}-\mathrm{C}_{10}$. The levels of deuteration varied from $16 \%$ with $25 \% \mathrm{D}_{2} \mathrm{O}+h$-glycerol to $90 \%$ with $100 \% \mathrm{D}_{2} \mathrm{O}+d$-glycerol. When $d$-tetradecane was used with $\mathrm{H}_{2} \mathrm{O}$, virtually all the deuterium appeared in the lipid chains while using $h$-tetradecane $+\mathrm{D}_{2} \mathrm{O}$ led to the majority of deuterium in the sugars. The adaptation to growth in deuterium appeared to be metabolic since no genetic changes could be found in the key rhamnolipid biosynthetic genes,
\end{abstract}

T. J. Smyth · A. Perfumo $\cdot$ I. M. Banat $(\square)$

School of Biomedical Sciences, University of Ulster,

Coleraine BT52 1SA, UK

e-mail: im.banat@ulster.ac.uk

R. Marchant

Research Office, University of Ulster,

Coleraine BT52 1SA, UK

M. Chen · R. K. Thomas $\cdot$ J. Penfold

Physical and Theoretical Chemistry Laboratory,

University of Oxford,

Oxford OX1 3QZ, UK

J. Penfold

ISIS Facility, Science \& Technology Facilities Council,

Rutherford Appleton Laboratory,

Didcot OX11 0QX, UK

P. S. Stevenson • N. J. Parry

Research and Development, Unilever,

Port Sunlight, Wirral,

Liverpool CH63 3JW, UK the rhamnosyl transferases $R h l B$ and $R h l C$. Deuterated sophorolipids were similarly produced using Candida bombicola and Candida apicola although in this case, no adaptation process was necessary. Up to 40 different sophorolipids were produced by these yeasts. However, unlike the rhamnolipids, use of $\mathrm{D}_{2} \mathrm{O}$ did not lead to any deuteration of the lipid chains, but direct incorporation into the lipid was achieved using $d$-isostearic acid. The results from these experiments show the feasibility of producing deuterated bioactive compounds from microorganisms coupled with the possibility of manipulating the pattern of labelling through judicious use of different deuterated substrates.

Keywords Deuterium · Deuterated - Biosurfactants · Bioactives $\cdot$ Rhamnolipids $\cdot$ Sophorolipids

\section{Introduction}

Isotopes of many of the biologically important elements have been used extensively for labelling and tracing metabolic pathways, either using radionuclides or heavy isotopes. These tracing methods are predicated on the view that the presence of alternative isotopes of elements does not disrupt the metabolic patterns of organisms, particularly microorganisms. Since the alternative isotopes often form only a small proportion of the total, as detection methods are highly sensitive, this assumption is normally true. However, the situation changes when dealing with deuterium ions otherwise known as 'heavy hydrogen', a stable isotope of hydrogen. When deuterium labelling of metabolites is required for neutron beam scattering (Russell et al. 2007) or NMR studies (Morgan et al. 2000), highly deuterated precursors are provided to 
organisms to obtain a high level of deuteration. Under these conditions, early studies noted no effect of $\mathrm{D}_{2} \mathrm{O}$ on bacteria up to about 20\% (De Giovanni and Zamenhof 1963; Thomson 1963), but at higher concentrations, growth rates were decreased significantly. Methods were subsequently developed to adapt or 'train' organisms to increasing levels of deuterated substrates in an effort to produce labelled products (Paliy et al. 2003; Newo et al. 2004). An alternative approach was employed with Chlorella vulgaris using alkylating agents to produce mutant strains which were able to tolerate deuterium (Unno et al. 2005) More recent work has focussed on trying to manipulate deuterium labelling in polyhydroxyoctanoate produced by Pseudomonas oleovorans for neutron scattering studies (Foster et al. 2006; Russell et al. 2007; Holden et al. 2008). Overall, interest in producing deuterated metabolites in microorganisms has been limited since their only application appeared to be for basic research studies (Myles 2006), but this is an area of increasing interest. There has also been renewed interest in this area, however, with the realisation that deuterated products may have specific biotechnological potential (Kushner et al. 1999), particularly in the pharmacology field where deuterated drugs may have a longer residence time in the body and with lower metabolic rates may be less toxic.

Research interest in our laboratories has focussed on biosurfactants as amphiphilic compounds with both hydrophilic and hydrophobic moieties able to help the producing microorganisms solubilise hydrophobic substrates (Desai and Banat 1997; Banat et al. 2000, 2010; Satpute et al. 2010; Perfumo et al. 2010a, b; Franzetti et al. 2010). As part of an investigation of the surface interactions of biosurfactant using neutron reflectivity ( $\mathrm{Lu}$ et al. 2000), we undertook to produce deuterated, rhamnolipids from $P$. aeruginosa and subsequently deuterated sophorolipids from the yeast $C$. apicola. Since our objective was to produce extensively labelled products with various alternative labelling patterns of the hydrophobic and hydrophilic portions of the molecules, we employed both deuterated water and deuterated carbon substrates. From this work, we can identify a strategy that may have wider application for the directed labelling of bioactive molecules with vast potential future applications.

\section{Materials and methods}

Organisms and growth media

The organisms used in this study were $P$. aeruginosa AD7 isolated from hydrothermal water (Perfumo et al. 2006), C. bombicola ATCC 22214 and C. apicola ATCC 96134. P. aeruginosa was routinely cultivated in LB broth (shaken at $200 \mathrm{rpm}$ ) or streaked on agar plates, all incubations were at $37^{\circ} \mathrm{C}$. The production medium for rhamnolipids was a mineral salts medium ${ }^{21}$ with $2 \%(v / v)$ glycerol or tetradecane. The Candida strains were maintained on YM medium (C. bombicola) or YEPD medium $(C$. apicola) and incubated at $27^{\circ} \mathrm{C}$. The production medium for sophorolipids (GYU) contained (g/l) glucose 100, yeast extract 10 , urea 1 , incubated at $200 \mathrm{rpm}$ and $27^{\circ} \mathrm{C}$. Cells were grown on GYU for $36-48 \mathrm{~h}$ (growth phase) before the second carbon substrate $(2 \% v / v$ isostearic acid or oleic acid) was added (production phase). Various deuterated substrates were used for the production of deuterated rhamnolipids and sophorolipids. Deuterated water was used as the basis for the growth medium with deuterated glycerol, deuterated tetradecane used for rhamnolipid production and deuterated isostearic acid used for sophorolipid production.

$P$. aeruginosa displayed significant growth inhibition when challenged with deuterated medium, containing either deuterated water or carbon substrate. To overcome the inhibition, the strain was 'trained' using a regime of increasing deuterium concentration separately in the water and carbon substrate. The regime for adaptation to deuterium was as follows: $\mathrm{D}_{2} \mathrm{O}-\mathrm{H}_{2} \mathrm{O}$ 25:75 2 days, 50:50 2 days, 75:25 3 days, 90:10 4 days, 100:0 5 days.

\section{Extraction procedures}

Deuterated rhamnolipids were extracted by centrifuging the culture broth at $15,000 \times \mathrm{g}$ for $15 \mathrm{~min}$ to remove cells. The $\mathrm{pH}$ was then adjusted to 2.0 using concentrated $\mathrm{HCl}$ followed by extraction with an equal amount of ethyl acetate (repeated four times). The ethyl acetate extract was dried over magnesium sulphate and rotary evaporated to yield a brown gum extract. Solid phase extraction was carried out using Silica SPE strata cartridges (Phenomenex, UK) to remove non-polar impurities co-extracted. SPE cartridges were conditioned with chloroform and the extracts applied and washed with chloroform removing non-polar lipids, followed by elution of rhamnolipids using 50:50 $(v / v)$ chloroform-methanol. The purified glycolipids were evaporated to dryness and dissolved in methanol prior to HPLC-MS analysis.

Extractions of deuterated sophorolipids were carried out in a similar manner to rhamnolipids above, without acidification since the low aqueous solubility of sophorolipids allows the material to separate directly. Once dried, excess co-extracted carbon source was removed by washing three times with hexane. Other non-polar impurities were removed using the SPE method as described above.

\section{Analytical characterisation}

HPLC-MS characterisation of the glycolipids was achieved using the $\mathrm{LCQ}^{\mathrm{TM}}$ quadrupole ion-trap mass spectrometer 
(Finnigan MAT, San Jose, CA, USA) utilising ESI connected to a thermo spectra HPLC system. Tandem mass spectrometry was carried out using collision energy of $35 \%$ throughout on the most intense peak in each MS scan. The scan range was set at $m / z 50-800$, with sheath gas flow set to 65 and the auxiliary gas to 35 . The spray voltage was set to $3.5 \mathrm{kV}$ and the capillary temperature to $250^{\circ} \mathrm{C}$. Nitrogen gas was delivered from a Whatman nitrogen generator (Whatman Inc. Haverhill, MA, USA), with the helium damping gas $(99.999 \%$ purity) present in the ion trap obtained from BOC Medical Gases (Guildford, Surrey, UK). HPLC-MS separation of the rhamnolipid mixtures utilised a reverse phase $\mathrm{C}_{18}$ column (Luna $5 \mu \mathrm{m} \mathrm{C}_{18}, 250 \times$ $4.6 \mathrm{~mm}$, Phenomenex) and a binary gradient mobile phase comprising HPLC grade $\mathrm{H}_{2} \mathrm{O}$ (BDH, Dorset, UK) as mobile phase $\mathrm{A}$ and acetonitrile (BDH, Dorset, UK) as mobile phase B. Initially, the proportions were $70 \%$ A, 30\% $\mathrm{B}$, adjusted in a linear gradient to $30 \% \mathrm{~A}, 70 \% \mathrm{~B}$ over $50 \mathrm{~min}$ and then back to $70 \% \mathrm{~A}, 30 \%$ B by $55 \mathrm{~min}$ and held for $5 \mathrm{~min}$. The flow rate of $0.5 \mathrm{ml} \mathrm{min}^{-1}$ and an injection volume of $20 \mu \mathrm{l}$ were used throughout.

Sophorolipid analysis was carried out using the same procedure as above with the following difference in the HPLC method. HPLC was performed using a reverse phase $\mathrm{C}_{18}$ column (Gemini $5 \mu \mathrm{m} \mathrm{C}_{18}, 250 \times 4.6 \mathrm{~mm}$, Phenomenex) and a binary gradient mobile phase comprising HPLC grade $\mathrm{H}_{2} \mathrm{O}$ as mobile phase A and acetonitrile as mobile phase $\mathrm{B}$. Initially, the proportions were $40 \% \mathrm{~A}, 60 \% \mathrm{~B}$, adjusted in a linear gradient to $10 \% \mathrm{~A}, 90 \% \mathrm{~B}$ over $55 \mathrm{~min}$ and then back to $40 \% \mathrm{~A}, 60 \%$ B by $57 \mathrm{~min}$ and held for $3 \mathrm{~min}$. The flow rate of $0.5 \mathrm{ml} \mathrm{min}^{-1}$ and an injection volume of $20 \mu \mathrm{l}$ were used throughout.

\section{Molecular methods}

Deuterium-adapted cells of $P$. aeruginosa AD7, designated AD7-d, were harvested from deuterated medium, pelleted and the genomic DNA extracted. The two rhamnosyl transferase genes RhlB and RhlC were selected for sequence comparison. The methods for DNA extraction, PCR (including primer sequences) and sequencing and subsequent bioinformatics handling of data are as follows. Genomic DNA was extracted using a commercial Fast DNA $^{\circledR} \operatorname{Spin}^{\circledR}$ Kit for Soil (BIO101, Carlsbad, CA), and cell lysis was performed with a FastPrep ${ }^{\mathrm{TM}}$ FP120 cell disrupter. PCR amplification of full-length $r h l B$ and $r h l C$ genes was carried out using newly designed sets of primers as follows:

rhlB2-f CATTTCCTCGACCTGGAGTC rhlB2-r ATCGAGAAAGCGTTGCAGTT rhlB3-f GGTACACCCCAAGTTCAACG rhlB3-r AAAAAGCCTCCGTCATTCCT

\section{rhlC2-f CTCGTCATTCTGGCTGGTCT rhlC2-r GCAGGCTGTATTCGGTGTC \\ rhlC3-f ATCCATCTCGACGGACTGAC rhlC3-r GGGCGATTCGTTCTACTTCC.}

PCRs were performed using the GC-RICH PCR systemdNTPack (Roche) with $\mathrm{MgCl}_{2}$ concentration adjusted to $2.5 \mathrm{mM}$. The PCR cycle was as follows: initial denaturation at $95^{\circ} \mathrm{C}$ for $3 \mathrm{~min}, 30$ cycles of denaturation at $95^{\circ} \mathrm{C}$ for $60 \mathrm{~s}$, annealing at $56^{\circ} \mathrm{C}$ for $60 \mathrm{~s}$, extension at $72^{\circ} \mathrm{C}$ for $90 \mathrm{~s}$ and final extension at $72^{\circ} \mathrm{C}$ for $10 \mathrm{~min}$. Sequencing reactions were prepared using an $\mathrm{ABI}$ Prism $^{\circledR}$ BigDye $^{\mathrm{TM}}$ Terminator reaction kit (Applied Biosystems, Foster City, CA) with addition of $5 \%(v / v)$ dimethyl sulfoxide and run on an ABI Prism ${ }^{\circledR} 3100$ Genetic Analyzer (Applied Biosystems). Each gene was sequenced in both forward and reverse direction with external and internal primers to produce overlapping fragments. Full-length sequences were obtained by assembling fragments with the CAP3 programme and for each gene forward and reverse contigs were aligned with ClustalW 2.0 to validate nucleotide match.

\section{Results}

Despite the adaptation, growth and rhamnolipid production in the fully deuterated medium was considerably lower than in non-deuterated medium. The Candida strains did not require any training regime to grow in deuterated media. The major results from the deuteration experiments for rhamnolipid and sophorolipid production are displayed in Tables 1 and 2, respectively. Analysis of the deuterated rhamnolipids produced in each experiment using HPLC-MS revealed the presence of up to 14 different structures including structural isomers, which is also generally observed during production of protonated rhamnolipids. Due to the complexity of the sample, only the main monorhamnolipid, L-rhamnosyl- $\beta$-hydroxydecanoyl- $\beta$-hydroxydecanoate designated as $\mathrm{Rha}-\mathrm{C}_{10}-\mathrm{C}_{10}$ and the main dirhamnolipid, L-rhamnosyl-L-rhamnosyl- $\beta$ hydroxydecanoyl- $\beta$-hydroxydecanoate designated as $\mathrm{Rha}_{2}-\mathrm{C}_{10}-\mathrm{C}_{10}$ are displayed in the table. Rha- $\mathrm{C}_{10}-\mathrm{C}_{10}$ has a molecular formula of $\mathrm{C}_{26} \mathrm{H}_{48} \mathrm{O}_{9}$ and under ESI-MS conditions using negative mode ionisation gives an $[\mathrm{M}-\mathrm{H}]^{-}$ signal at $\mathrm{m} / \mathrm{z} 503$, representing the loss of a proton from the molecular mass of the compound during ionisation. $\mathrm{Rha}_{2}-$ $\mathrm{C}_{10}-\mathrm{C}_{10}$ contains a dirhamnose sugar attached to the fatty acid chain and displays an $[\mathrm{M}-\mathrm{H}]^{-}$signal at $\mathrm{m} / z 649$ in the non-deuterated form and corresponds to the molecular formula $\mathrm{C}_{32} \mathrm{H}_{58} \mathrm{O}_{13}$ (Figs. 1 and 2).

In each experiment, rather than one single $\mathrm{Rha}-\mathrm{C}_{10}-\mathrm{C}_{10}$ or $\mathrm{Rha}_{2}-\mathrm{C}_{10}-\mathrm{C}_{10}$ structure being produced by the microor- 
Table 1 Production of $d$-rhamnolipids using combinations of deuterated water and/or carbon sources

\begin{tabular}{|c|c|c|c|c|c|c|}
\hline Deuterium/carbon source & Rhamnolipid structure & Range of d-ions $(\mathrm{m} / \mathrm{z})$ & Average (main) & $\% d$-atoms & Sugar & Lipid \\
\hline \multirow[t]{2}{*}{$d$-tetradecane } & $\mathrm{Rha}_{2}-\mathrm{C}_{10}-\mathrm{C}_{10}$ & $677(28 d)-683(34 d)$ & $680(31 d)$ & 54 & $311(2 d)$ & $368(29 d)$ \\
\hline & Rha- $\mathrm{C}_{10}-\mathrm{C}_{10}$ & $531(28 d)-536(33 d)$ & $534(31 d)$ & 66 & $164(1 d)$ & 369 (30d) \\
\hline \multirow[t]{2}{*}{$50 \% \mathrm{D}_{2} \mathrm{O}+d$-tetradecane } & $\mathrm{Rha}_{2}-\mathrm{C}_{10}-\mathrm{C}_{10}$ & $684(35 d)-694(45 d)$ & $690(41 d)$ & 72 & $317(8 d)$ & $371(32 d)$ \\
\hline & Rha- $\mathrm{C}_{10}-\mathrm{C}_{10}$ & $534(31 d)-544(41 d)$ & $539(36 d)$ & 77 & $169(5 d)$ & $370(31 d)$ \\
\hline \multirow[t]{2}{*}{$100 \% \mathrm{D}_{2} \mathrm{O}+h$-tetradecane } & $\mathrm{Rha}_{2}-\mathrm{C}_{10}-\mathrm{C}_{10}$ & $666(17 d)-671(22 d)$ & $669(20 d)$ & 35 & $324(15 d)$ & $344(5 d)$ \\
\hline & Rha- $\mathrm{C}_{10}-\mathrm{C}_{10}$ & $514(11 \mathrm{~d})-518$ (15d) & $516(13 d)$ & 28 & $172(9 d)$ & $343(4 d)$ \\
\hline \multirow[t]{2}{*}{$50 \% \mathrm{D}_{2} \mathrm{O}+h$-tetradecane } & $\mathrm{Rha}_{2}-\mathrm{C}_{10}-\mathrm{C}_{10}$ & $656(7 d)-664(15 d)$ & $659(10 d)$ & 18 & $316(7 d)$ & $341(2 d)$ \\
\hline & Rha- $\mathrm{C}_{10}-\mathrm{C}_{10}$ & $507(4 d)-512(9 d)$ & $510(7 d)$ & 15 & $168(5 d)$ & $341(2 d)$ \\
\hline \multirow[t]{2}{*}{$25 \% \mathrm{D}_{2} \mathrm{O}+h$-glycerol } & $\mathrm{Rha}_{2}-\mathrm{C}_{10}-\mathrm{C}_{10}$ & $655(6 d)-662(12 d)$ & $658(9 d)$ & 16 & $311(2 d)$ & $346(7 d)$ \\
\hline & Rha- $\mathrm{C}_{10}-\mathrm{C}_{10}$ & $508(5 d)-514(8 d)$ & $508(8 d)$ & 17 & $164(1 d)$ & $346(7 d)$ \\
\hline \multirow[t]{2}{*}{$50 \% \mathrm{D}_{2} \mathrm{O}+h$-glycerol } & $\mathrm{Rha}_{2}-\mathrm{C}_{10}-\mathrm{C}_{10}$ & $661(12 d)-670(21 d)$ & $666(17 d)$ & 28 & $312(3 d)$ & $352(13 d)$ \\
\hline & Rha- $\mathrm{C}_{10}-\mathrm{C}_{10}$ & $513(10 \mathrm{~d})-522(19 \mathrm{~d})$ & $518(15 d)$ & 32 & $165(2 d)$ & $351(12 d)$ \\
\hline \multirow[t]{2}{*}{$75 \% \mathrm{D}_{2} \mathrm{O}+h$-glycerol } & $\mathrm{Rha}_{2}-\mathrm{C}_{10}-\mathrm{C}_{10}$ & $672(23 d)-680(31 d)$ & $676(27 d)$ & 47 & $315(6 d)$ & 359 (20d) \\
\hline & Rha- $\mathrm{C}_{10}-\mathrm{C}_{10}$ & $524(21 d)-530(27 d)$ & $527(24 d)$ & 51 & $166(3 d)$ & 359 (20d) \\
\hline \multirow[t]{2}{*}{$90 \% \mathrm{D}_{2} \mathrm{O}+h$-glycerol } & $\mathrm{Rha}_{2}-\mathrm{C}_{10}-\mathrm{C}_{10}$ & 679 (30d)-689 (40d) & $684(35 d)$ & 61 & 317 (8d) & $366(27 d)$ \\
\hline & Rha- $\mathrm{C}_{10}-\mathrm{C}_{10}$ & $531(28 d)-539$ (36d) & $535(32 d)$ & 68 & $168(5 d)$ & $366(27 d)$ \\
\hline \multirow[t]{2}{*}{$100 \% \mathrm{D}_{2} \mathrm{O}+h$-glycerol } & $\mathrm{Rha}_{2}-\mathrm{C}_{10}-\mathrm{C}_{10}$ & 687 (38d)-693 (44d) & $690(41 d)$ & 72 & $318(9 d)$ & $371(32 d)$ \\
\hline & Rha- $\mathrm{C}_{10}-\mathrm{C}_{10}$ & $537(34 d)-543(40 d)$ & $540(37 d)$ & 79 & $167(4 d)$ & $371(32 d)$ \\
\hline \multirow[t]{2}{*}{$d$-glycerol } & $\mathrm{Rha}_{2}-\mathrm{C}_{10}-\mathrm{C}_{10}$ & $658(9 d)-664(15 d)$ & $661(12 d)$ & 21 & $316(7 d)$ & $344(5 d)$ \\
\hline & Rha- $\mathrm{C}_{10}-\mathrm{C}_{10}$ & $508(5 d)-514(11 d)$ & $511(7 d)$ & 15 & $166(3 d)$ & $343(4 d)$ \\
\hline \multirow[t]{2}{*}{$100 \% \mathrm{D}_{2} \mathrm{O}+d$-glycerol } & $\mathrm{Rha}_{2}-\mathrm{C}_{10}-\mathrm{C}_{10}$ & 698 (49d)-702 (53d) & $700(51 d)$ & 89 & $326(17 d)$ & $373(34 d)$ \\
\hline & Rha- $\mathrm{C}_{10}-\mathrm{C}_{10}$ & 544 (41d)-548 (45d) & $546(43 d)$ & 91 & $172(9 d)$ & $373(34 d)$ \\
\hline
\end{tabular}

Only the main dirhamnolipid, $\mathrm{Rha}_{2}-\mathrm{C}_{10}-\mathrm{C}_{10}$ (fully protonated $\mathrm{m} / \mathrm{z}$ of 649 ) and the main monorhamnolipid, $\mathrm{Rha}-\mathrm{C}_{10}-\mathrm{C}_{10}$, (fully protonated $\mathrm{m} / \mathrm{z}$ of 503) are displayed. HPLC-MS results are displayed showing the range of deuterated compounds produced, the percentage incorporation of deuturium and their relative position within the structure

ganism, a range containing different amounts of deuterium incorporation were observed. The range of deuterium ions was calculated from the $\mathrm{m} / \mathrm{z}$ difference between the deuterated and protonated structures and has a lower and upper limit depending on the number of different deuterium structures produced for each rhamnolipid. Only those above a $25 \%$ relative abundance in relation to the highest abundant structure are recorded. In each experiment, the middle of this range was also the most abundant ion observed, and this value was used to calculate the percentage deuterium incorporated. The lowest percentage of deuterium of $16-17 \%$ was observed for the experiment using $25 \%$ heavy water and protonated glycerol as the carbon sources. While the highest level of around $90 \%$

Table 2 Production of d-sophorolipids using combinations of deuterated water and/or carbon sources

\begin{tabular}{|c|c|c|c|c|c|}
\hline Deuterium/carbon source & Sophorolipid structure & Range of d-ions $(\mathrm{m} / \mathrm{z})$ & Average (main) & $\% d$-atoms & Lipid \\
\hline \multirow[t]{2}{*}{$50 \% \mathrm{D}_{2} \mathrm{O}$} & A, 2 Ac, C18:1 & 709 (4d)-717 (12d) & $713(8 d)$ & 14 & $299(2 d)$ \\
\hline & L, 2 Ac, C18:1 & $691(4 d)-699(12 d)$ & $695(8 d)$ & 15 & $299(2 d)$ \\
\hline \multirow[t]{2}{*}{$d$-isostearic acid } & A, 2 Ac, C18:1 & $740(35 d)-742(37 d)$ & $741(36 d)$ & 63 & $331(34 d)$ \\
\hline & L, 2 Ac, C18:1 & $722(35 d)-724(37 d)$ & 723 (36d) & 65 & $331(34 d)$ \\
\hline \multirow[t]{2}{*}{$\mathrm{D}_{2} \mathrm{O}+$ oleic acid } & A, 2 Ac, C18:1 & $714(7 d)-722(17 d)$ & 718 (13d) & 23 & $298(1 d)$ \\
\hline & $\mathrm{L}, 2$ Ac, C18:1 & $695(7 d)-703(16 d)$ & $699(13 d)$ & 24 & $298(1 d)$ \\
\hline \multirow[t]{2}{*}{$\mathrm{D} 2 \mathrm{O}+$ disostearic acid } & A, 2 Ac, C18:1 & 749 (34d)-759 (44d) & 755 (40d) & 89 & $331(34 d)$ \\
\hline & $\mathrm{L}, 2 \mathrm{Ac}, \mathrm{C} 18: 1$ & $731(44 d)-740(53 d)$ & 737 (50d) & 93 & $331(34 d)$ \\
\hline
\end{tabular}

Only the main lactonic sophorolipid with two acetyl groups and a C18:1 lipid chain (fully protonated $\mathrm{m} / \mathrm{z}$ of 687 ) and the main acidic sophorolipid with two acetyl groups and a C18:1 lipid chain (fully protonated $\mathrm{m} / \mathrm{z}$ of 705 ) are displayed. HPLC-MS results are displayed showing the range of dueterated compounds produced, the percentage incorporation of deuturium and the amount located on the lipid chain 
deutad7d2050\%normal gly_080201142627 \#780-1863RT:15.23-37.61AV:542NL:6.62E5

F:- c ESI Full ms [ 50.00-1000.00]

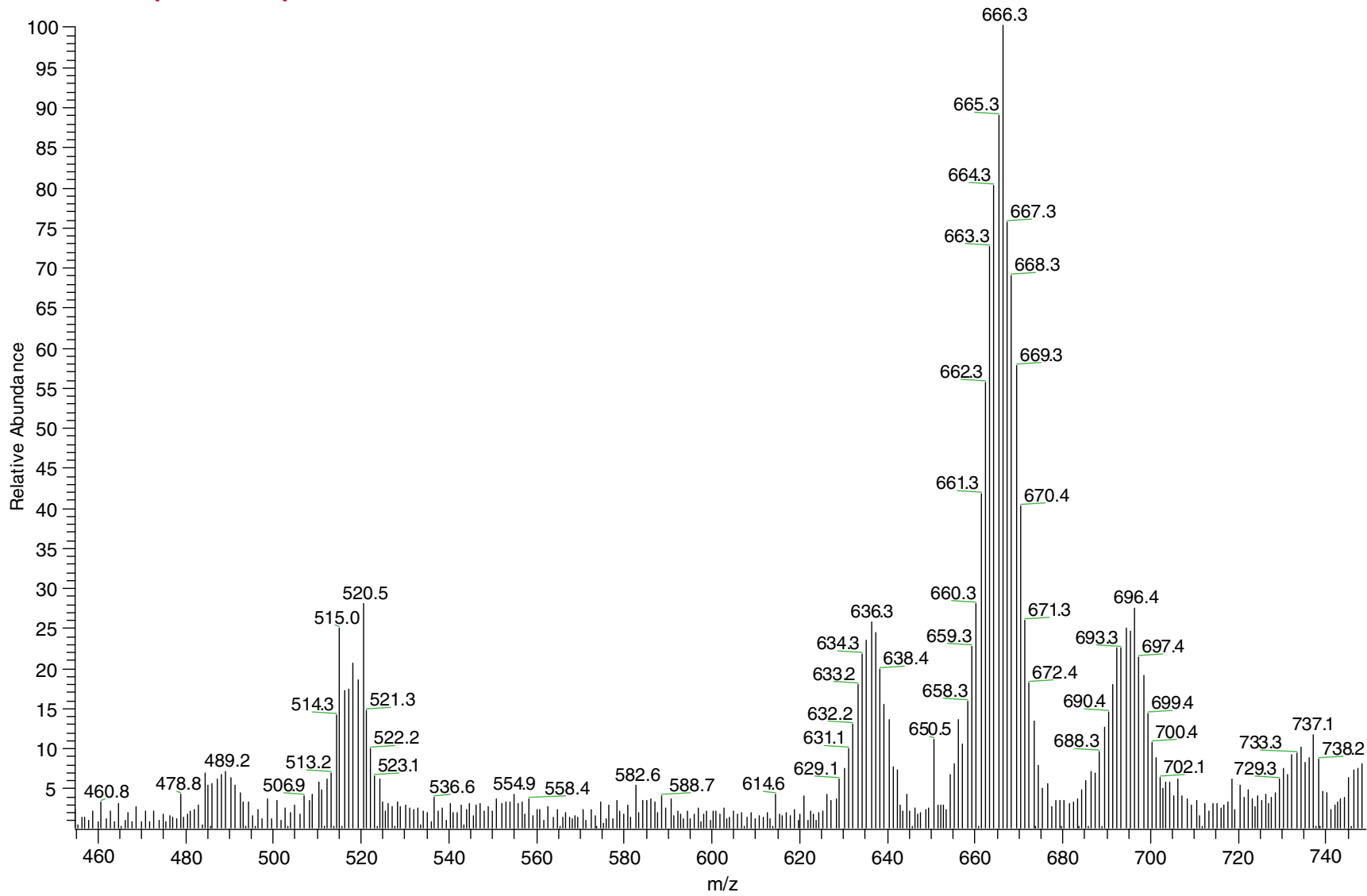

Fig. 1 HPLC-MS showing the TIC spectrum of $d$-rhamnolipids produced using 50/50 water/heavy water and protonated glycerol. Each of the major rhamnolipids is represented by a bell-shaped peak with each line representing the same structure with one more or less $d$ atoms present

resulted in rising levels of $d$-atom incorporation on the lipid chain from 13 to $32 d$-atoms, while the rhamnose portion also increased. When the only source of deuterium was present in glycerol, only $4 / 5 d$-atoms were incorporated on the fatty acid portion with the remainder present on the sugar group, suggesting that when no alkane or fatty acid is present during production, water is heavily involved in the biosynthesis of the lipid portion. The production using both $\mathrm{D}_{2} \mathrm{O}$ and $d$-glycerol resulted in the greatest level of deuterated rhamnolipids with $34 d$-atoms on the lipid chain and 17 and nine $d$-atoms on the dirhamnose and monorhamnose moieties, respectively. The use of mixtures of heavy and normal water along with protonated or deuterated carbon source resulted in a large range of $d$-atoms incorporated. For example, when 50/50 heavy and normal water was used with $d$-tetradecane, the range of $d$-atoms for each type of rhamnolipid was 10 . The use of $100 \% \mathrm{D}_{2} \mathrm{O}$ and $d$-glycerol resulted in a range of four different levels for each rhamnolipid product, suggesting the use of highly pure carbon sources and water results in a much less complex mixture of rhamnolipids being produced. 
C:XCaliburl...lad7 100\% d20 and d-gly $\quad$ 15/04/2008 09:55:54

ad7 100\% d20 and d-gly \#2-7RT:0.02-0.11AV:6NL:1.70E7

F:- c Full ms [ 150.00-1200.00]

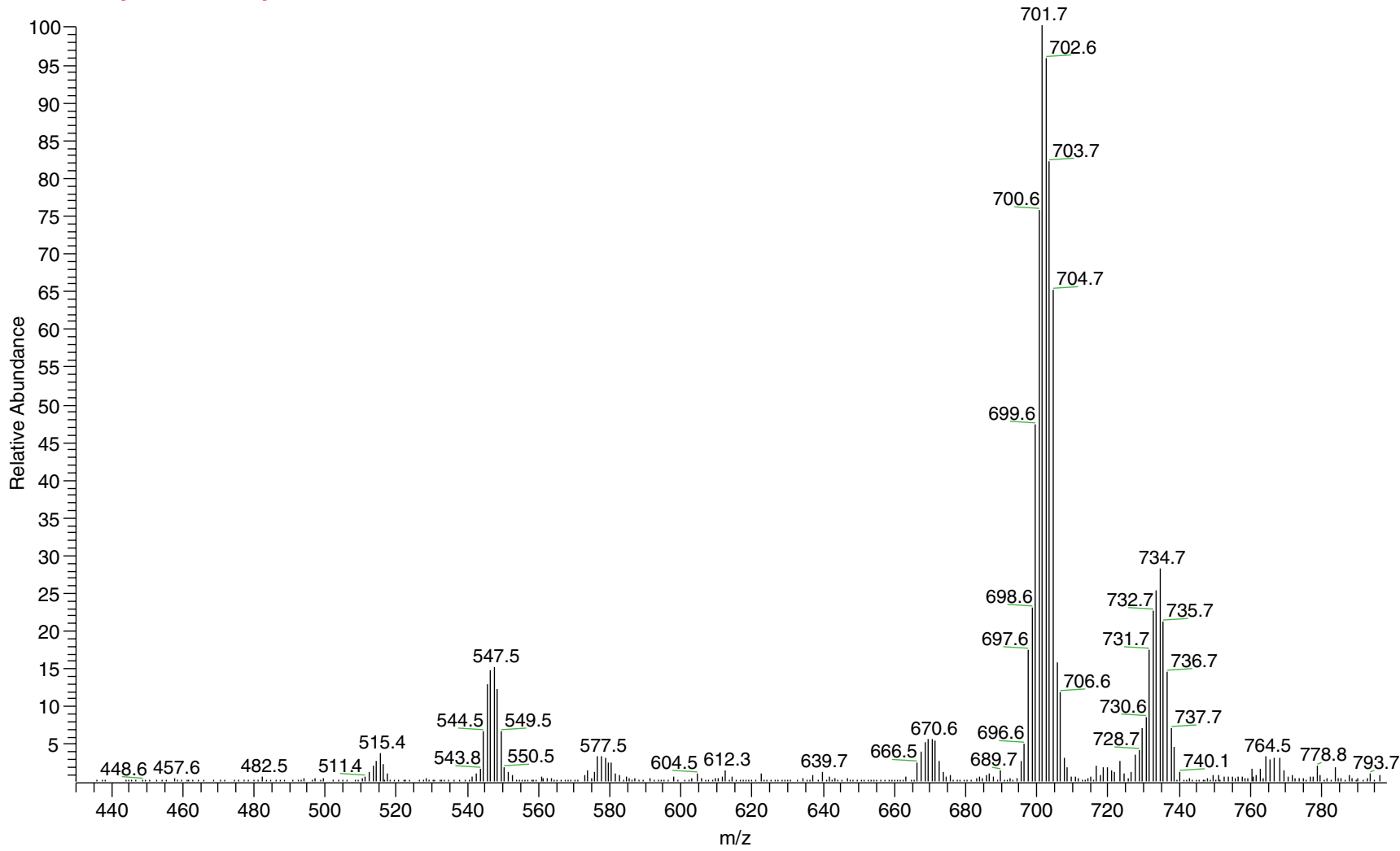

Fig. 2 HPLC-MS showing the TIC spectrum of $d$-rhamnolipids produced using $100 \% \mathrm{D}_{2} 0$ and $d$-glycerol, showing a much smaller range of $d$ atoms for each structure

Generally, the production of sophorolipids results in an even more complex mixture being produced, containing anywhere from 20 to 40 different sophorolipids and associated isomers. The sophorolipids produced can be split into two groups, acidic and lactonic, with only the main acidic and lactonic forms displayed in Table 2. The main acidic, 17-L-[(2'-O- $\beta$-D-glucopyranosyl- $\beta$-D-glucopyranosyl)oxy] octadecenoic acid- $6^{\prime}, 6^{\prime \prime}$-diacetate, has a molecular formula of $\mathrm{C}_{34} \mathrm{H}_{57} \mathrm{O}_{15}$ giving an $[\mathrm{M}-\mathrm{H}]^{-}$signal at $m / z 705$ in the fully protonated form. Under negative mode ionisation, the main lactonic, 17-L-[(2'-O- $\beta$-D-glucopyranosyl$\beta$-D-glucopyranosyl)-oxy] octadecenoicacid-1,4"-lactone-6',6"diacetate, gives a signal at $\mathrm{m} / \mathrm{z} 687$ corresponding to the molecular formula $\mathrm{C}_{34} \mathrm{H}_{55} \mathrm{O}_{14}$ minus one proton, which occurs during ionisation. During MS/MS fragmentation, only the ion representing the fatty acid portion could be detected and only at a low abundance compared to other major fragments that were present.

Using 50\% heavy water and no fatty acid carbon sources resulted in an extremely small quantity of $d$-sophorolipids being produced with two $d$-atoms incorporated in the lipid chain and another six $d$-atoms presumably on the sugar moiety. With $100 \% \mathrm{D}_{2} \mathrm{O}$ and oleic acid, $13 d$-atoms were present with 12 on the sophorose group. Unlike $d$ rhamnolipid where the water source was capable of influencing the level of deuterium incorporated into the lipidic chain, no such effect was observed for $d$-sophorolipid biosynthesis. Direct incorporation of deuterium into the fatty acid portion was achieved using deuterated isostearic acid, resulting in $34 d$-atoms being present, with only two $d$ atoms in the sugar portion when normal water was also used. Cultivation using heavy water and $d$-isostearic acid resulted in roughly $90 \%$ deuterium being present in each main structure with 34 and $16 d$-atoms on the lipid and sugar portions, respectively.

Rhamnolipid gene resequencing from adapted strain and comparison with wild-type strain

Direct comparison of the complete gene sequences for $R h l B$ (the mono-rhamnosyl transferase) and RhlC (the dirhamnosyl transferase) in the deuterium adapted strain AD7- $d$, and its parent strain AD7 showed that there had been no genetic modification of two of the key genes 
involved in rhamnolipid synthesis; therefore, the adaptation process had almost certainly been metabolic adaptation. The accession numbers for the gene sequences for strain AD7 are $R h l B$ FN601361 and $R h l C$ FN601388.

\section{Discussion}

The initial target for this work was the production of rhamnolipids and sophorolipids with high levels of deuteration (at least 50\%) that could be used for neutron scattering studies of the surface adsorption properties of the biosurfactants. As the work progressed, using $\mathrm{D}_{2} \mathrm{O}$ and other deuterated carbon sources, we realised that the incorporation patterns in the biosurfactants could be manipulated through judicious use of $\mathrm{D}_{2} \mathrm{O}$ and the other substrates. Two clear conclusions can be drawn from the experiments carried out. First, when high levels of deuterium are provided to prokaryotes, either in the form of $\mathrm{D}_{2} \mathrm{O}$ or deuterated carbon substrate, high levels of initial inhibition of growth occur. This inhibition can be overcome by adopting a progressive adaptation strategy so that eventually, although growth is still restricted, satisfactory levels of production can be achieved. The adaptation of the prokaryotes is metabolic and does not appear to be based in genetic modification of the key genes in the metabolic pathway. This is of significant importance as it means that there are no changes in the key metabolic pathway products. Eukaryotic microorganisms do not suffer the same level of deuterium inhibition as prokaryotes although adaptation may still be necessary to achieve effective growth (Haon et al. 1993; Morgan et al 2000). Kushner et al. (1997) stated 'mechanisms involved in such adaptation have hardly been studied' and the situation appears to be largely unchanged at the present time. Paliy et al (2003) recognised that the adaptation of Escherichia coli to growth on deuterated minimal medium could not be clearly identified as solely due to metabolic adaptation or genetic mutation but suggested that a range of non-specific mutations were involved in the process.

The second conclusion is that careful selection of deuterated substrates can be used to achieve selective labelling of products. In the case of the biosurfactants, which consist of a hydrophilic portion comprising sugar molecules and a hydrophobic tail composed of lipid chains, the sugar portion can be effectively labelled with the use of $\mathrm{D}_{2} \mathrm{O}$ only while the lipid chains can be heavily labelled using an appropriate deuterated carbon substrate. These results together indicate the feasibility of production of deuterated bioactive microbial products in which the exact pattern of labelling could be manipulated to give optimum efficacy. In the case of biosurfactants with wide potential medical application (Rodrigues et al. 2006, 2007), this may have significant implications with regards to persistence and or efficacy in the human body.

Wider implications of the ability to manipulate the level of deuteration in various bioactive molecules such as antibiotics and other drugs is modifying the physicochemical structures of such compounds which may lead to different efficacy, persistence or increased challenges to the development of microbial resistance. An area of great future interest we believe will be determining whether site directed, selective or specifically deuterated antibiotics are an effective strategy against drug-resistant microorganisms. Partial success of improved effectiveness compared to the protonated forms against sensitive organisms would lead to the ability to use lower doses and higher efficiency against resistant organisms. Achieving the latter would open vast area of research and industrial interest in the use of deuterated compounds in numerous biomedical and health related applications.

Other potential uses include selective labelling of parts of target drugs to monitor their breakdown or dissociation within biological systems. Both naturally existing microbial products and other new products can be produced using deuterated water and substrate. Eguchi et al. (2005) produced deuterated zeaxanthin, lycopene and $\beta$-carotene using a genetically engineered $E$. coli on deuterated mevalonate as one of the growth substrates to study the physicochemical properties of these substrates. Finally, the increased availability of highly deuterated microbial bioactive compounds may encourage research activity into their monitoring, biochemistry, durability, developing resistance and therefore, possibly extend their uses.

Acknowledgements This work has been carried out with the financial support of TSB (formerly DTI) and Unilever UKCR grant number $\mathrm{HO667H.}$

\section{References}

Banat IM, Makkar SR, Cameotra SS (2000) Potential commercial application of microbial surfactants. A review article. Appl Microbiol Biotechnol 53:495-508

Banat IM, Franzetti A, Gandolfi I, Bestetti G, Martinotti MG, Fracchia L, Smyth TJ, Marchant R (2010) Microbial biosurfactants production, applications and future potential. Appl Microbiol Biotechnol (in press)

De Giovanni R, Zamenhof S (1963) Studies on incorporation of deuterium into bacteria. Biochem J 87:79-82

Desai JD, Banat IM (1997) Microbial production of surfactants and their commercial potential. Microbiol Molecular Biol Rev 61:4764

Eguchi T, Dekishima Y, Aizawa H, Tamegai H, Kakinuma K, Misawa N, Kuzuyama T, Seto H (2005) Preparation of highly deuterated zeaxanthin, lycopene, and b-carotene from fully deuterated mevalonate using engineered Escherichia coli. Tetrahedron 61:2027-2035 
Foster LJR, Russell RA, Sanguanchaipaiwong V, Stone DJM, Hook JM, Holden PJ (2006) Biosynthesis and characterization of deuterated polyhydroxyoctanoate. Biomacromolecules 7:13441349

Franzetti A, Tamburini E, Banat IM (2010) Applications of biological surface active compounds in remediation technologies. In: Sen R (ed) Biosurfactants, vol. 672. Springer, Heidelberg, pp 121-134

Haon S, Auge S, Tropis M, Milon A, Lindley ND (1993) Low cost production of predeuterated biomass using methylotrophic yeasts. J Label Compd Radiopharm 33:1053-1063

Kushner DJ, Baker A, Dunstall TG (1997) Biotechnological potential of heavy water and deuterated compounds. Proceedings of Biotechnology Risk Assessment Symposium, Ottawa, Canada, June 23-25, 1996. Edited by M Levin C Grim JS Angle. University of Maryland Biotechnology Institute Publication 1003, pp 75-89

Kushner DJ, Baker A, Dunstall TG (1999) Pharmacological uses and perspectives of heavy water and deuterated compounds. Can J Physiol Pharmacol 77:79-88

Lu JR, Thomas RK, Penfold J (2000) Surfactant layers at the air/water interface: structure and composition. Adv Coll Int Sci 84:143304

Morgan WD, Kragt A, Feeney J (2000) Expression of deuteriumisotope-labelled protein in the yeast Pichia pastoris for NMR studies. J Biomolec NMR 17:337-347

Myles DAA (2006) Neutron protein crystallography: current status and a brighter future. Curr Opin Struct Biol 16:630-637

Newo ANS, Pshenichnikova AB, Skladnev DA, Shvets VI (2004) Deuterium oxide as a stress factor for the methylotrophic bacterium Methylophilus sp. B-7741. Microbiol 73:175-179

Paliy O, Bloor D, Brockwell D, Gilbert P, Barger J (2003) Improved methods of cultivation and production of deuteriated proteins from $E$. coli strains grown on fully deuterated minimal medium. J Appl Microbiol 94:580-586
Perfumo A, Banat IM, Canganella F, Marchant R (2006) Rhamnolipid production by a novel thermophilic hydrocarbon-degrading Pseudomonas aeruginosa APO2-1. Appl Microbiol Biotechnol 72:132-138

Perfumo A, Smyth TJP, Marchant R, Banat IM (2010a) Production and roles of biosurfactants and bioemulsifiers in accessing hydrophobic substrates. In: Timmis KN (ed) Handbook of hydrocarbon and lipid microbiology, vol. 2. Springer, Heidelberg, pp 1501-1512

Perfumo A, Rancich I, Banat IM (2010b) Possibilities and challenges for biosurfactants use in petroleum industry. In: Sen R (ed) Biosurfactants, vol. 672. Springer, Heidelberg, pp 135-145

Rodrigues L, Banat IM, Teixeira J, Oliveira R (2006) Biosurfactants: potential applications in medicine. $\mathrm{J}$ Antimicrob Chemother 57:609-618

Rodrigues L, Banat IM, Teixeira J, Oliveira R (2007) Strategies for the prevention of microbial biofilm formation on silicone rubber voice prostheses. J Biomedical Materials Res, Part B-Applied Biomaterials 81:358-370

Russell RA, Holden PJ, Wilde KL, Harnmerton KM, Foster LJR (2007) Production and use of deuterated polyhydroxoctanoate in structural studies of PHO inclusions. J Biotechnol 132:303-305

Holden RRA, Wilde KL PJ, Hammerton GCJ, Foster LJR KM (2008) In vivo deuteration strategies for neutron scattering analysis of bacterial polyhydroxyoctanoate. Eur Biophys J 37:711-715

Satpute SK, Banpurkar AG, Dhakephalkar PK, Banat IM, Chopade BA (2010) Methods for investigating biosurfactants and bioemulsifiers: a review. Crit Rev Biotechnol (in press)

Thomson JF (1963) Effects of deuterium on microorganisms. In: International series of monographs on pure and applied biology - modern trends in physiological sciences, pp 61-75

Unno K, Hagima N, Kishido T, Okada S, Oku N (2005) Deuteriumresistant algal cell line for $\mathrm{D}$ labelling of heterotrophs expresses enhanced level of Hsp60 in $\mathrm{D}_{2} \mathrm{O}$ medium. Appl Env Microbiol 71:2256-2259 